\title{
"Vaguely Like a Man": The Theism of Charles S. Peirce
}

PEIRCE'S THEISM is not calculated to please many philosophersat least not at first sight. His theism, he says, is "sound pragmatism," and this is not likely to attract positivists who have adopted its maxim as an expression of their own views concerning verification. His theism, he says, is a consequence of anthropomorphisma claim not likely to enthuse either traditional theists or hardheaded scientists. Finally, his theism is intrinsically infected with vagueness, a disease which surely will be diagnosed as fatal by many analysts and logicians. I have failed to remark perhaps the most disturbing claim of all: Peirce's theism is supported by a form of the ontological argument! This will perhaps please no one at all.

Yet there it is in all its outrageous boldness: a theism supported by an "exact logician" trained in natural science; a theism that is the consequence of pragmatism; a theism vague and anthropomorphic, and, therefore, indubitable in the strictest sense. These are hard words, and who among philosophers will hear them? The point of this essay is to help the philosopher, if he is still willing to read on, to understand the precise import of these shocking claims and perhaps suggest at least that they are not so shocking - that, in the end, they are not so bad even if unusual and/or distasteful.

In a letter to William James (July 23, 1905), Peirce remarked that his own belief in theism was "good sound solid strong pragmatism" (8.262). Three years later he published his well-known "Neglected Argument for the Reality of God" (6.452-493) in the Hibbert Jour-

An earlier version of this chapter appeared in God Knowable and Unknowable, ed. Robert J. Roth, S.J. (New York: Fordham University Press, 1973), pp. 241-54. 
nal where he gave a "poor sketch" of that argument and a mere "table of contents" of what would be required to show its validity. This poor sketch is in reality a rapid and terse outline of that philosophical view called "pragmaticism" which he had elaborated over the preceding half-century. The "table of contents" is nothing but a marshaling of the conclusions he had reached concerning the nature of reasoning worked out with so much labor over that same period.

In a short essay I cannot hope to do justice to Peirce's thought on this matter. I will simply try here to expound some of his reflections which may serve as a propaedeutic to his well-known article in the hope that it will aid the reader, first, to understand the unusual kind of argument it is, and, second, to help focus properly critical evaluation. I will not attempt an analysis of the argument itself; that alone would require an essay or two. I restrict myself, then, to preliminaries: what Peirce had to say about God-talk in general and why in general he held what he did. While this essay does not seek critical evaluation in recto, it does so in obliquo, since it pretends not only to expound but also to explain and interpret. That explanation and interpretation intend to be a presentation of the truth of the matter as this writer sees it, while at the same time remaining faithful to Peirce. The presentation will consist of three parts: (1) traditional theism, (2) anthropomorphic theism, (3) vagueness.

\section{Traditional Theism}

In a letter to William James (June 12, 1902), Peirce says that he has been reading Royce's The World and the Individual and finds it not in very good taste "to stuff it so full of the name of God" (8.277). The reason is that "the Absolute is strictly speaking only God, in a Pickwickian sense, that is, in a sense that has no effect" (8.277). The point of this remark seems to be that, although it may be true that God is absolute, such a characterization is altogether too abstract and formal to make of God an object of belief. An object of belief in the strict sense according to Peirce must be such that it is capable of influencing human conduct. Peirce seems to think that Royce's absolute if not allowed other attributes would 
be precisely incapable of such influence because it is too abstract and empty. It is God in a Pickwickian sense, in a sense that has no effect, and so literally is incapable of belief. The reality (or unreality) of God as merely "the Absolute" would make no difference to human conduct. Whatever attributes over and above "absoluteness" we decide "God" must have, they must be such as to show God to be intimately related to and "concerned with" what men do. To be an object of belief, the reality of God must make a difference to human conduct. The meaning of "God," then, must be rooted in human experience and at the same time must indicate in some way that that reality is not confined to space and time. Let us consider how Peirce describes the absolute reality called "God."

In the opening lines of his article on the Neglected Argument, Peirce defines the term "God" as the definable proper name signifying Ens necessarium (6.452). This reality is not only necessary but also one, personal, not immanent in creation but creating the universe $(5.496,6.505-506)$, omniscient (6.508), omnipotent (6.509), infallible (6.510), not subject to time (4.67), and not finite (8.262). These attributes are recognizable as the traditional ones of theistic natural theology. But what is different in Peirce's description is that he will not allow that God exists, in the strict sense of that term, but rather that he is real (cf. 8.262). The reason is that existence strictly belongs to the category of Secondness, of brute force or interaction. Whatever belongs to Secondness must be capable of action and reaction and must, therefore, be spatiotemporal. Consequently, such a reality would be limited and finite. But this will not do for God, since he is the Creator of the three universes of which the actual - the realm of existents-is but one. God, then, must be said to be real (as opposed to unreal, fictitious, non-being) but not to exist.

The term of Peirce's argument, therefore, is a non-finite, necessary reality that can best be described in traditional theistic terms, because such a description makes of that reality more than an abstract and empty Absolute. It makes of that reality something that would make a difference to human conduct if acknowledged as real. It is a conception that would arise from meditation upon human experience and which in turn would affect that experience insofar as it is subject to self-control. It was such considerations 
as these which led Pierce to try to write down a description of his argument:

If God really be, and be benign, then, in view of the generally conceded truth that religion, were it but proved, would be a good outweighing all others, we should naturally expect that there would be some Argument for His Reality that should be obvious to all minds, high and low alike, that should earnestly strive to find the truth of the matter; and that this Argument should present its conclusion, not as a proposition of metaphysical theology, but in a form directly applicable to the conduct of life, and full of nutrition for men's highest growth. (6.457)

In a word, Peirce believed that there is no more adequate way for us to conceive of the adequate cause of the universe than as vaguely like a man (5.536). The theistic notion of God, then, is both anthropomorphic and vague. According to Peirce, it is precisely because that notion is anthropomorphic that it is believable and because it is vague that it is a notion of God.

\section{ANTHROPOMORPHIC THEISM}

Peirce's claim that theism must be anthropomorphic to be believable is, to say the least, unusual. One might have expected that a theist would try to avoid the charge of anthropomorphism as an objection to any theory of God. The medieval theologians were at pains to avoid precisely this sort of objection by developing at length a negative theology and a doctrine of analogous predication. Whether these attempts by some of the leading proponents of theism were successful or not is not the point here; what is important is the lengths to which defenders of theism have gone in order to avoid this sort of criticism. And yet not only does Peirce not reject the allegation, he seems to revel in it.

What, then, does he understand by anthropomorphism? Peirce contrasts his use of this term with Schiller's "humanism." While humanism is allied with anthropomorphism and is in perfect harmony with pragmatism, it does not deal precisely with the same question, because Schiller, in Peirce's view, identifies it with the "old humanism" which was not so much a scientific opinion as an 
aim. Pragmatism as a scientific opinion is best expressed by the term "anthropomorphism." The scientific opinion to which Peirce refers is, of course, the correct analysis of scientific method at which all his logical researches were directed. It is this analysis which implies theism:

if by metaphysics we mean the broadest positive truths of the psycho-physical universe . . . then the very fact that these problems can be solved by a logical maxim is proof enough that they do not belong to metaphysics but to "epistemology," an atrocious translation of Erkenntnislehre. (5.496)

Among other things, Erkenntnislehre shows that man has powerful and accurate instincts besides reasoning. In fact, reasoning is nothing but a development of instinct and so is continuous with it. Instinct is more basic than reasoning, and no adequate account of reasoning and scientific research can be given without recognizing its role. This, of course, is not to say that reasoning is identical with instinct. It is not. But a correct analysis of scientific reasoning will show, according to Peirce, its roots in human instinct. Thus Peirce can say:

For those metaphysical questions which have such interest [human interest], the question of a future life and especially that of One Incomprehensible but Personal God, not immanent in but creating the universe, I, for one, heartily admit that a Humanism, that does not pretend to be a science but only an instinct, like a bird's power of flight, but purified by meditation, is the most precious contribution that has been made to philosophy for ages. (5.496; emphasis added)

Peirce argues that almost all human conceptions are at bottom anthropomorphic. This is true even of scientific hypotheses, and to say that an hypothesis is unscientific simply because it is anthropomorphic is an objection "of a very shallow kind, that arises from prejudices based upon much too narrow considerations" (5.47). According to Peirce, this is the objection for the nominalist. In opposition to these "much too narrow considerations," Peirce maintains that all man's knowledge, including all scientific and philosophical theories and hypotheses which can have any meaning, is based upon experience. 
I hold . . . that man is so completely hemmed in by the bounds of his possible practical experience, his mind is so restricted to being the instruments of his needs, that he cannot, in the least, mean anything which transcends those limits. (5.536)

All man's conceptions, then, are anthropomorphic, in the sense that they depend upon the limits of his possible experience. But to say this is like passing a law forbidding man to jump over the moon; such a law would not prevent him from jumping as high as he could. Man will continue to try to conceive of a supreme and indeed transcendent cause or agency of the entire universe, but there will be no more adequate way of conceiving than "as vaguely like a man." Furthermore, Peirce repeatedly recalls that the only satisfactory explanation of man's ability to form any hypothesis applicable to the universe is his affinity to the universe.

And in regard to any preference for one kind of theory over another, it is well to remember that every single truth of science is due to the affinity of the human soul to the soul of the universe, imperfect as that affinity no doubt is. To say, therefore, that a conception is one natural to man, which comes just about to the same thing as to say that it is anthropomorphic, is as high a recommendation as one could give to it in the eyes of an Exact Logician. (5.47)

Peirce's anthropomorphism, therefore, is nothing other than his metaphysical realism.

They [the great realists] showed that the general is not capable of full actualization in the world of action and reaction but is of the nature of what is thought, but that our thinking only apprehends and does not create thought, and that that thought may and does as much govern outward things as it does our thinking. (1.27)

The basic mistake of nominalism is that it violates the fundamental rule of exact logic: do not block the road to inquiry. By denying that anything is real except the actual, it at once renders all knowledge of the world inexplicable and posits an unknowable "thingin-itself." It renders knowledge of the world inexplicable because all knowledge of the world involves generals. If generals are not real but only figments of the mind, then knowledge is not of the world. Rather, it posits a mere "out-there-here-and-now," about which nothing can be said, conceived, or judged. It would be 
positing the utterly unintelligible and inexplicable as the ultimate explanation, thus cutting off all further questions and inquiry. For Peirce such a position turns out to be in the strictest sense meaningless in view of the pragmatic maxim.

The elements of every concept enter into logical thought at the gate of perception and make their exit at the gate of purposive action and whatever cannot show its passports at both of those gates is to be arrested as unauthorized by reason. (5.212)

Peirce's "anthropomorphism," it must be concluded, is but another name for his realistic pragmatism (pragmaticism).

\section{VAGUENESS}

Theism, it has been remarked, is only implied by anthropomorphism. The middle term, as it were, for this inference is to be found in Peirce's critical common-sensism, itself a consequence of pragmaticism (5.439). It is so, in my view, because it takes seriously the role of "instinctive mind" by which man has an affinity to nature (5.47) and to God (8.262; see 6.516).

Our logically controlled thoughts compose a small part of the mind, the mere blossom of a vast complexus, which we may call instinctive mind, in which this man will not say he has faith, because that implies the conceivability of distrust, but upon which he builds as the very fact to which it is the whole business of his logic to be true. (5.212)

This "instinctive mind" through which every concept enters into logical thought Peirce elsewhere calls "Insight ... into Thirdnesses, the general elements, of Nature." Again he refers to it as a "faculty" that man must have, because otherwise there would be no accounting for his undeniable ability to guess right among the millions of possible hypotheses often enough to allow him to make genuine discoveries (5.171ff.). This is man's il lume naturale, the natural disposition with which man comes into the world (see $1.80,2.750,5.47,5.603-604,6.10,5.504)$. Ultimately, then, instinctive mind must consist of "in posse innate cognitive habits, which is all that anybody but John Locke ever meant by innate ideas" (5.504). 
Instinctive mind, then, is "pre-scientific"; it is the ground of reasoning both as an activity and as a developed habit; it is the affinity of the mind to reality which makes any scientific inquiry possible. Insofar as science strives for greater and greater precision in its terms and concepts, instinctive mind will escape scientific analysis. It will always remain vague and indeterminate because it is the innate source and origin of reasoning itself whose function to a large extent is to analyze and make precise what it apprehends. No attempt to inquire scientifically into instinctive mind (no matter how useful and informative such investigation may prove to be) can be adequate to the reality so investigated. Something will always be "left over" which is vague and indeterminate. This is true not only of instinctive mind but also of any reality investigated by science. The real is continuous and so intrinsically affected by vagueness and generality, both forms of indeterminateness. This is why the real is intelligible, why it must be said to be "mind-like," and why, finally, there is any affinity between human minds and the universe.

The point that I am trying to make is that for Peirce it is a serious mistake not to take vagueness seriously. It would be an even greater mistake to think that whatever remains vague after investigation can be disregarded as unreal. And perhaps the greatest mistake of all would be to think that in principle all vagueness can be eliminated even from science in the strictest sense. These errors in understanding human knowing are found in varying forms and degrees in the several nominalistic interpretations of inquiry. Peirce's pragmaticism was meant to avoid them. Critical commonsensism and "scholastic" realism, both consequences of pragmaticism, argue for vagueness and generality as essential ontological as well as logical categories.

In an attempt to show that there is nothing contradictory in holding a common-sensism that is at the same time critical, Peirce lists six characteristics that distinguish his position from the Scotch school. The fourth and most important of these he states as follows:

By all odds, the most distinctive character of the Critical-Commonsensist, in contrast to the old Scotch philosopher [Reid], lies in his insistence that the acritically indubitable is invariably vague.

Logicians have been at fault in giving Vagueness the go-by, so far as even to analyze it. (5.446; see 5.505) 
The recognition of vagueness as an important logical category is essential to Peirce's discussion of theism. Our ideas of the infinite are extremely vague, he writes to James, and become contradictory the moment we attempt to make them precise (8.262). It is true to say of God that $\mathrm{He}$ is omniscient and omnipotent providing that we leave these concepts vague (6.508-509). And yet these predicates "are not utterly unmeaning" for, as a matter of fact, they can be interpreted "in our religious adoration and the consequent effects upon conduct” (8.262). The vagueness of our notions of God, therefore, ought not for that reason rule them out from rational belief. Indeed, this vagueness acts as a corrective to anthropomorphism by negating the limitation of human experience and classification in the infinite reality. In a word, it is vagueness that allows our notions to be about God.

Vagueness is a form of indeterminateness. Generality is another. A subject is said to be determinate with respect to a character when that character is predicated of it universally and affirmatively. Such a subject, of course, would also be determinate with respect to the negative of such a character. In all other respects the subject is indeterminate. A sign is objectively general if it leaves it to the interpreter to supply further determinations. Thus, in the sentence "Man is mortal" the term "man" is objectively general because the answer to the question "Which man?" is "Any one you choose." A sign is objectively vague if it reserves for some other possible sign (and not for the interpreter) the function of completing the determination. Thus, in the sentence "This month a great event will happen," the term "great event" is objectively vague because the answer to the question "Which event?" is not "Any one you like" but rather "Let us wait and see" (5.447, 5.505). Now, every utterance leaves the right of further exposition to the utterer, and so every utterance is to that extent vague. Its vagueness is removed to the extent that the signs it uses are rendered general. According to Peirce, it is usually the case that an affirmative predication covers generally every essential character of the predicate, while a negative predication vaguely denies some essential character (5.447). It turns out, therefore, that in every communication situation absolute determinateness and precision are not and cannot be attained: 
honest people, when not joking, intend to make the meaning of their words determinate, so that there shall be no latitude of interpretation at all. That is to say, the character of their meaning consists in the implications and the non-implications of their words; and they intend to fix what is implied and what is not implied. They believe that they succeed in doing so, and if their chat is about the theory of numbers, perhaps they may. But the further their topics are from such precise, or "abstract," subjects, the less possibility is there of such precision of speech. (5.447; see also 2.357)

Another way of distinguishing vagueness and generality as two forms of indeterminateness is as follows: "anything is general insofar as the principle of excluded middle does not apply to it and is vague insofar as the principle of contradiction does not apply to it" (5.448; cf. 5.505). Thus, Peirce observes, a triangle in general is not isosceles, not equilateral, not scalene. It is false neither that an animal (in a vague sense) is male nor that an animal is female (5.505). While no sign can be both vague and general in the same respect, still every sign is to some extent indeterminate and to that degree is both vague and general. The only way in which it could escape being either vague or general would be for it to be completely and absolutely determinate. According to Peirce, this is simply not possible. While every proposition actually asserted must refer to some non-general subject, still no communication between persons can be entirely non-vague. The reason for this, without going into detail, is that there is no such thing as a logical atom in the strict sense, that is, a term incapable of logical division (see 3.93). It follows, then, that none of our conceptions, even the most intellectual and scientific, are absolutely precise, that is, without some vagueness.

Peirce holds that our acritically indubitable beliefs are invariably vague. To submit such beliefs to criticism involves an attempt to render them more precise. To the extent that they are rendered more precise, Peirce admits that they are open to doubt. His point is this: "Yet there are beliefs of which such a critical sifting invariably leaves a certain vague residue unaffected" (5.507). The question, then, is simply whether that vague residue itself would disappear under persevering attempts at precision.

But the answer ... is that it is not because insufficient pains have been taken to precise the residuum, that it is vague: it is that it is vague intrinsically. (5.508) 
The example of such an indubitable belief offered by Peirce is that of order in nature. A host of critics have submitted to criticism every precise statement of that order which has been proposed. Each of these precise statements is open to doubt. "As precisely defined it can hardly be said to be absolutely indubitable considering how many thinkers there are who do not believe it" (5.508). All this shows, however, is that any precise statement of nature's order is open to doubt. In fact, it is the very precision that allows room for doubt and therefore for criticism. And yet for all that, "who can think that there is no order in nature" (5.508)? For Peirce, such a claim is literally unthinkable. Pure chaos cannot be thought; the notion of chaos itself is parasitical upon the notion of order; it is relative disorder, that is relative to an order we expected to find or hoped to find. Any number of doubts can be cast upon this or that or the other characterization of nature's order, but there always remains a vague residue to that original belief which cannot be done away with. This residue is indubitable and indeed acritical, but it is not indubitable precisely because it is acritical in the sense of simply not having been criticized. Rather, it remains indubitable because it cannot be criticized since it remains essentially vague.

Peirce is convinced that there is a relatively fixed list of such original beliefs which is the same for all men. He tells us that he was not always so convinced but that experience and reflection led him to this view. He admits to always having been strongly attracted by a form of common-sensism which holds that there is "no definite and fixed collection of opinions that are indubitable, but that criticism gradually pushed back each individual's indubitables, modifying the list, yet still leaving him beliefs indubitable at the time being" (5.509). A better understanding of vagueness, however, changed his mind. From very early on (at least from the paper "Some Consequences of Four Incapacities" in 1868), Peirce held that there is no first, indubitable proposition that occupies a privileged epistemic position. This basic criticism of what he took to be the "spirit of Cartesianism" is compatible with the position outlined in the preceding paragraph. Every proposition is indeed open to criticism, revision, and doubt to the extent that it is precise, that is, non-vague. On the other hand, every proposition remains to some extent and in some respect vague; otherwise it simply would not function as a symbol (see 2.357). Every proposi- 
tion, therefore, is to be interpreted in terms of another proposition and thus ad infinitum.

To the extent that the vagueness of a proposition is intrinsic to it, that proposition remains an element of the indubitable. Hence, every proposition is open to revision both in the sense that it can always give way to a more adequate expression and in the sense that an erroneous proposition (that is, a false proposition) can give way to a true one. Indubitables in the sense of primitive, original beliefs are indubitable because they remain intrinsically vague not only with respect to the individual logical subjects to which they refer but also with respect to the character or characters predicated of them. No amount of analysis will render those predicates absolutely precise and determinate since they will always carry the rider "vaguely like." This rider, of course, warns the hearer or reader that some unspecified character of that predicate does not apply to the subject, and so that the subject is also vaguely unlike the character applied to it. Some predicates, for example, infinite, omnipotent, etc., carry this warning in themselves since they contain in their own comprehension the negation of some general predicate (non-vague in that respect).

Perhaps all this is not well put and an example might be worth a thousand vague and general explanations. Let us consider Peirce's own example: there is order in nature. The logical subject of this indubitable is a non-vague, non-general reality vaguely and generally characterized in the first place by the predicate "nature" and further specified by the vague and general predicate "order." What is intended in this proposition is not at all indefinite, and consequently the subject term partakes of the nature of an index in that it functions so as to force attention on its object. Still, the logical subject of a symbol is not strictly an index because it indicates its object only as a result of being intended to do so (a true index is a sign independently of anyone's intending it to be). Since only a true index can be absolutely determinate and since the subject of a proposition is only like an index, the logical subject of our proposition is not absolutely non-vague. This sort of vagueness attaches to the logical subject of any proposition whatsoever.

This is what Peirce means by saying that there is no logical atom. Both predicates in our example are also vague and intrinsically so. "Nature" is vague because it is understood to be the denial of 
"artifact" and, further, is a collective term for all such non-artifacts. More precision can be accomplished only by further indicating what "nature" is not or by pointing to objects that go to make up "nature" without being nature-natural objects. The positive content of that term remains imprecise although not empty on that account. "Order" is vague because it is a relational term and can be made precise only with respect to some standards of comparison antecedently specified. What this comes to is that this or that particular order might be rendered non-vaguely indicated, but not order as such. Similarly, non-order is a relative term. It indicates the absence of some anticipated kind of order. But absolute nonorder is literally unthinkable and cannot be even vaguely indicated. Since non-order is not real in any absolute sense at all, it has no positive content at all. It is pure negativity-the limit notion of "no thought at all." The proposition under consideration, then, is at least doubly vague, with respect to its subject and with respect to its predicates. ${ }^{1}$ Its predicates are vague not because of any lack of diligence on the part of analysts but because of their very nature. Order is unity amid multiplicity-one and many-and, of course, this is the paradox!

Belief in the God of theism is for Peirce an original belief. It is one of the indubitables in that relatively fixed list that is the same for all men. Doubts about God's reality or about the attributes that most aptly describe Him arise from attempts at precision. Every formula about God which claims to be non-vague is to that extent open to real doubt. The ultimate ground for such doubt is the fact that insofar as such formulas succeed in being precise they are false. An infinite being is not the sort of thing that can be precisely classified. If it were, then it would fall under a genus and so would entail the possibility of many Gods (8.262). Doubts about God's reality, therefore, are in fact doubts about various formulas meant to express that reality in relatively non-vague terms. Such doubts, however, are not about God's reality; indeed for Peirce such a doubt is impossible because belief in it is instinctive; it is an acritical indubitable in the sense already discussed. Doubt about it, according to Peirce, vanishes once it is recognized that all appropriate formulations of that reality are intrinsically vague. Thus Peirce claims that any argument for God's reality is really a form of the ontological argument. 


\section{Note}

1. Peirce remarks that "indefiniteness and generality might primarily affect either the logical breadth or the logical depth of the sign to which it belongs" (5.448, note). In the case of a proposition, logical breadth is the subject denoted and logical depth is the predicate asserted (5.471; see 2.394ff.). 